colour. The whole nose is thicizened and enlarged by a tough inelastic deposit. The relness nearly reaches the cheek on the left, and on the right sicle extends some clistance on the face; the whole surface is studded with angry pimples and blotches. The sore itself covers the right ala nasi, has eaten through it in one part, and extends upon the top of the nose and upon the right cheek.

She states that in February, 1854,-that is, mearly three years previous to my seeing her, the disease appeared on the right side of the nose as a number of small pimples; these increased in size and number, and in about eight months broke out into an open sore. She has since that time unclergone a great deal of treatment: the sore has been burnt with nitric acid, with potassa fusa, and nitrate of silver, of which applications she has great dread, and under which she did not in prove.

A purified preparation of catechu, made by dissolving several times, pouring off the clear liquor, and evaporating to the consistence of treacle, was spread upon linen, aud applied over the reddened skin and ulcer; this was continued daily. The redness diminished to a considerable degree, and the pimples seemed less angry. In three weeks, however, the discharge began to increase again, and the application was changed to a strong decoction of oak bark. This preparation also answered for a month extremely well; the size and congestion of the parts continuing to diminish.

On the 10th of February tannic acid was used: it was dissolved in as small a quantity as possible of water, and applied with a camel's-hair brush. Each application almost instantly reduced the redness of the skin, and dried into a scab, which on the following day was removed, and a reapplication made. This treatment went on for some time, the sore decreasing in size. Occasionally a little disturbance in health would throw her back for a time; but still the improvement was tolerably uninterrupted.

On the 15th of May I began to diminish the strength of the tannic acid to so thin a solution that it did not form a seab, and this $I$ let her apply night and morning.

On the 22nd of June the solution used was only of the strength of twenty grains to the ounce, and on the $6 \mathrm{th}$ of July the sore was healed and the redness had nearly disappeared. It is probable that, in a short time, only the scar of the old ulceration will be left.

Burlington-street, July, 1857.

\section{RECOVERY AFTER SWALLOWING A LARGE QUANTITY OF ARSENIC.}

\section{BY THOMAS GODFREY, EsQ., M.R.C.S. \& L.S.A.,} Mansfield.

A MDDDLE-AGED woman, in perfect health, and of violent and impetuons temper, swallowed, in a paroxysm of rage and jealousy, a quantity of arsenic, equal in bulk to about a dessertspoonful. This she mixed in half a cupful of water, and swallowed it, having partaken freely, a few minutes before, of an abundant dinner of meat and suet pudding. Her violent excitement having soon after subsided, she confessed the fact, having previously informed her sisters, who witnessed the aet, that she had taken magnesia. I arrived in about one hour and a half from the time of her swallowing the dose; and being unaware of the nature of the occurrence, could only exhibit an emetic of sulphate of zinc, which I happened to have with me. This produced frequent romiting, which was promoted by repeated draughts of warm water. Having obtained hydrated peroxide of iron from my surgery, for which I had to send one mile and a half, $I$ administered it freely, suspended in treacle and water, so that in three hours from the time of swallowing the arsenic, she had drank abont four pints of water, and from seven to eight ounces of the peroxide, no portion of which was retained beyond five minutes. At one time the prostration became alarming, the pulse bein $:$ rapid, and barely appreciable, the features distorted, cold perspiration of the body, and severe rigor.

In five honrs from taking the arsenic, she resolutely refused to swallow more liquid; and as she lad rallied considerably, and appeared drowsy, she was permitted to sleep for seven hours. when she appeared quite recovered, and free from any 114 suspicious symptom beyond a slight epigastric tenderness, which I referred to the frequent vomiting, but for which, as a precautionary measure, I prescribed calomel and opium. In twenty-four hours from this time, I discontinued the pills; nor was there any indication for further treatment, her convalescence fullowing so rapidly that in five days she had resumed her domestic duties.

Notts, July, 1857.

\section{a 3 Atruror}

OF THE PRACTICE OF

\section{MEDICINE AND SURGERY IN THE}

\section{HOSPITALS OF LONDON.}

Nulla est alia pro certo noscendi vich, nisi quam plurimas et morborum e dissectionum historias, tam aliornm proprias, collectas habere et inter se com parare.-Morgagnr. De Sed. et Cauls. Morb. lib. 14. Prowmium.

\section{GUY'S HOSPITAL.}

ALC THE VIARIETIES OF TUMOUR BELONGING TO THE CLASS ADENOCELE DEVELOPED WITHIN A SINGLE PREAST; SUCCFSSFUL EXTIRPATION; THE GLAND ASSUNTNG ITS NORMAL OUTLINE.

\section{(Under the care of Mr. Birizetr.)}

ONE of the most remarkable, interesting, and instructive examples of the development of all the known forms of inno. cent tumours affecting the mammary gland within a single breast we saw at this hospital some weeks back. The new growth was what Mr. Birlett described as an epitome of every variety of tumour which belongs to the great class adenocele, an account of which disease he has fully given in the first volume of the third series of "Guy's Hospital Reports."

In the tumour which was remored from the breast, under the influence of chloroform, we saw in the centre the chronic mammary tumour of Sir Astley Cooper, the pancreatic sarcoma of Abernethy, the sero-cystic disease of Brodie, the carcinoma mammæ hydatidis of Sir Chas. Bell, one of the forms of hydatid disease of the breast of Sir A. Cooper; in fact, every form of innocent growth in the breast described by such names.

The varieties of adenocele in the mammary gland are exhibited under three very different forms and aspects, and we have established, Mr. Birkett thinks by Nature, three very marked divisions of these growths. These are of such interest in connexion with the case which we report to day, that we offer no apology for giving them:-

"The first division consists of new growths, which are compact, dense, firm, fibrous, lobed on their surface and in their interior, and enveloped in their own fibrous capsule. The second, of cystoid formations, having growths within them, which appear to spring from their walls; these growths being loose, pedunculated, and floating or sessile, and with no connective lissue between them, its place being often supplied by fluid. And the third, of cystoid formations, distinctly referable to the dilatation of a duct, or to a connexion with one, and containing growths which appear to spring from their walls." -p. 138.

Mr. Birkett has included in the first division those tumours termed by Sir A. Cooper, "chronic mammary tumour;" by Cruveilhier, "corps tibrenx;" by Lebert, "bypertrophie partielle ;" by Velpean, " tmmour adenoide ;" by Paget, "mammary glandular tumour." In the second, the tumour described by Sir A. Cooper, "hydatid disease of the breast;" by Müller, as "cysto-sarcoma" by Sir Charles Bell, "carcinoma mamma hydatidis;" by Sir Benjamin Brodie, "serocystic tumours;" by Paget, "proliferous cysts." In the third, the variety described by Sir B. Brodie, in his Lectures illustrative of various subjects in Pathology and Surgery, as arising "by a dilatation of portions of some of the lactiferous tubes,"

We cannot venture into a consideration of all these; but it has been shown by Mr. Birkett that they preponderate in single women. He has given as many as 45 in 62 cases; and 